Article

\title{
Panic Buying and Consumption Displacement during COVID-19: Evidence from New Zealand
}

\author{
C. Michael Hall ${ }^{1,2,3,4, *(\mathbb{D})}$, Peter Fieger ${ }^{5,6}{ }^{(D)}$, Girish Prayag ${ }^{7}(\mathbb{D})$ and David Dyason ${ }^{8,9}(\mathbb{D})$ \\ 1 Department of Management, Marketing and Entrepreneurship, University of Canterbury, \\ Christchurch 8140, New Zealand \\ 2 Department of Service Management and Service Studies, Campus Helsingborg, Lund University, \\ 25108 Helsingborg, Sweden \\ 3 Geography Research Unit, University of Oulu, 90014 Oulu, Finland \\ 4 Ekonomihögskolan, Linnéuniversitet, Universitetskajen, Landgången 6, 39182 Kalmar, Sweden \\ 5 School of Education, Federation University, Mount Helen, VIC 2351, Australia; p.fieger@federation.edu.au \\ 6 Business School, University of New England, Armidale, NSW 2351, Australia \\ 7 UC Business School, Department of Management, Marketing and Entrepreneurship, \\ University of Canterbury, Christchurch 8140, New Zealand; girish.prayag@canterbury.ac.nz \\ 8 Faculty of Agribusiness and Commerce, Lincoln University, Lincoln 7647, New Zealand; \\ David.Dyason@lincoln.ac.nz \\ 9 TRADE Research Entity, School of Economic Sciences, North-West University, \\ Potchefstroom 2520, South Africa \\ * Correspondence: michael.hall@canterbury.ac.nz
}

check for updates

Citation: Hall, C. Michael, Peter Fieger, Girish Prayag, and David Dyason. 2021. Panic Buying and Consumption Displacement during COVID-19: Evidence from New Zealand. Economies 9: 46. https:// doi.org/10.3390/economies9020046

Academic Editor: Bruce Morley

Received: 28 February 2021

Accepted: 26 March 2021

Published: 1 April 2021

Publisher's Note: MDPI stays neutral with regard to jurisdictional claims in published maps and institutional affiliations.

Copyright: (c) 2021 by the authors. Licensee MDPI, Basel, Switzerland. This article is an open access article distributed under the terms and conditions of the Creative Commons Attribution (CC BY) license (https:/ / creativecommons.org/licenses/by/ $4.0 /)$.

\begin{abstract}
Panic buying and hoarding behavior is a significant component of crisis- and disasterrelated consumption displacement that has received considerable attention during the COVID-19 pandemic. Understanding such purchasing and stockpiling behavior provides critical information for government, disaster managers and the retail sector, as well as policy makers to adjust crisis response strategies and to better understand disaster management, including preparedness and response strategies. This study examines consumer purchasing behavior, retail spending and transactional data for different retail sectors between January 2017 and December 2020 using data for the greater Christchurch region in New Zealand. Once COVID-19-related panic buying began, overall spending increased sharply in anticipation of lockdowns. Transactional spending increased and subsided only slowly to a level higher than pre lockdown. The magnitude of the panic buying event far exceeded historical seasonal patterns of consumer spending outside of Christmas, Easter and Black Friday, although daily spending levels were comparable to such consumption events. The results of the study highlight the importance of comparing panic buying to other events in terms of purchasing motivations and also considering that so-called panic buying may contribute to greater individual and household resilience. The volume of sales alone is not adequate to define panic buying. Instead, the extent of divergence from the normal daily spending value per retail transaction of a given population provides a much more accurate characteristic of panic buying.
\end{abstract}

Keywords: panic-buying; displacement; stockpiling; COVID-19; retail spending

\section{Introduction}

Fear, panic and insecurity are an integral human response to crisis and disaster, with responses being dependent on a range of individual and socio-economic factors (e.g., culture, economic security, gender, personality) as well as proximity to the source of risk (Bonneux and Van Damme 2006; Michie and West 2020; Qian and Li 2020; Tan et al. 2020; Yang and Xin 2020). The understanding of such behaviors is regarded as critical in improving the quality of crisis and disaster response as well as individual, economic and regional resilience with respect to existing and future crisis events (Coles and Buckle 2004; Bristow 2010; Modica and Reggiani 2015; Karatzias et al. 2017; Van Bavel et al. 2020; Kowal et al. 2020; Ye et al. 2020; Benker 2021). 
A topic that is a feature of disaster- and crisis-related insecurity is panic buying and stockpiling behavior, with such consumer and, to a lesser extent, organizational behavior being a widely reported response to COVID-19 intervention measures enacted by government (Remko 2020; Yoshizaki et al. 2020; Islam et al. 2021; Taylor 2021). Understanding such purchasing and stockpiling behavior provides critical information for government, disaster management organizations and the retail sector, as well as policy makers to adjust crisis response strategies (Wang et al. 2020; Wang and Hao 2020). From a business perspective it can also allow for better management and adjustment of inventory and can improve supply chain management while maintaining consumer satisfaction (Brandtner et al. 2021). Panic buying affects the shopper experience, with empty store shelves and an absence of required products, while hoarding behavior can threaten the stability of the food system (Wang et al. 2020; Wang and Hao 2020), especially in import-reliant cities and regions (Song et al. 2021). Experience with crises and disasters, including COVID-19, also indicates that product categories may be differentially affected over time (Kirk and Rifkin 2020).

Hoarding or stockpiling is the act of collecting and safeguarding a large quantity of possessions for future use (Chu 2018). Consumer hoarding during COVID-19 were likely to be primarily affected by government public health interventions that served to constrain consumers' normal consumption behaviors and practices (Hall et al. 2020), e.g., in terms of where, when and how to purchase; supply chain disruptions (Kirk and Rifkin 2020; and social media (Zhao and Zhou 2020; Leung et al. 2021), and sensationalist media reporting (Arafat et al. 2020b). This was manifested by product scarcity on shelves, most recognizably with respect to a seeming global concern with the availability of toilet paper (Garbe et al. 2020; Loxton et al. 2020; Yoshizaki et al. 2020; Leung et al. 2021; Taylor 2021), and aggressive instore consumer behavior. Perry and Lindell (2003) argued that in the event of a disaster most people do not develop panic flight responses. Instead, "behaviour in the disaster response period is generally pro-social as well as rational" (Perry and Lindell 2003, p. 50). However, although it is suggested that panic buying tends to influence a relative minority of people and disappears in a short time period (Ballantine et al. 2014; Yuen et al. 2020), Perry and Lindell (2003) were primarily writing in terms of specific disaster events of limited scale rather than a national and global event such as COVID-19. Panic buying is not necessarily caused by a supply deficit per se, although perceptions of a future deficit are significant, but by consumers' heightened anxiety and fear (Tsao et al. 2019). In the case of COVID-19, all of these factors were applicable. Various conceptual definitions of panic buying exist, with some focusing on the impulsive and obsessive behavior (Islam et al. 2021; Naeem 2020), others focusing on hoarding or stockpiling behavior (Wang et al. 2020). However, the majority attempted to define panic buying and hoarding from a perspective of consumer behavior and psychology and in isolation from the actual pattern of consumption over time which, arguably, is just as significant with respect to understanding the economic, social and organizational response implications of such behavior.

This paper therefore examines consumer purchasing behavior, retail spending and transactional data from the city of Christchurch in New Zealand for different retail sectors during the COVID-19 pandemic. However, unlike existing studies of panic buying, this research seeks to position the COVID-19 response within a longitudinal context so that the differences between panic buying and other periods of low frequency, high-magnitude consumption periods, such as Christmas, can be better identified and evaluated. In addition, we seek to identify if there are any longer-term implications of panic buying and hoarding on consumer purchasing behavior. This is also significant as previous research (Hall et al. 2020) has argued that disaster and crisis events, such as earthquakes and health crises, need to be better understood with respect to their capacity to displace consumption and be analyzed over the longer-term with respect to their effects on regional consumption and economic systems rather than as immediate events, as significant as they may appear at the time. Such a perspective is also far more in keeping with the different stages of a crisis or disaster that are recognized in disaster management (mitigation/prevention, preparedness, 
response, and recovery) and which can be used to better prepare for future crises (Khan et al. 2008; Hall et al. 2016; Rahmi et al. 2019).

\subsection{Panic Buying as a Consumer Response}

Panic buying is a complex behavior fueled by diverse and multiple motives and psychological processes (Dholakia 2020; Yuen et al. 2020). It is usually regarded as a psychological reaction in response to stress, anxiety, depression, fear and uncertainty about the future (Dholakia 2020; Dubey et al. 2020; Mukhtar 2020). Food hoarding and stockpiling as exemplars of this behavior represent an attempt to take control of a chaotic situation, reduce fear and insecurity, and therefore represents a coping mechanism for individuals (Arafat et al. 2020a, 2020b). Stockpiling addresses two fundamental psychological needs of individuals (Lopes et al. 2020; Loxton et al. 2020; Zhang and Smith 2020; Herjanto et al. 2021). First, it allows individuals to feel that they have exerted a degree of control when the environment surrounding them is chaotic and they feel that the associated risks are uncontrollable, fatal or have catastrophic potential for themselves. Second, fear of the unknown that heighten risk perceptions during a crisis can also be attributed to panic buying (Slovic 1987; Yuen et al. 2020). A perception of relative scarcity is also potentially strongly linked to panic buying of particular product categories, while this behavior can also be driven by lack of trust and anticipation of a decline in consumption options (Dholakia 2020).

Panic buying has also been approached from several different theoretical perspectives of consumer behavior. Kirk and Rifkin (2020) argue that hoarding is the first of a three-stage process, where consumers react, then cope and in the long-term adapt to environmentally imposed constraints. In the short-term fear and anxiety, for example, prompt consumers to take action in the face of an imminent threat. These negative emotions also cause cognition and attention deployment, which can sway individuals toward focusing on immediate needs and protect themselves against future harm (Kemp et al. 2021). From a social learning theory perspective, people learn by observing the behaviors of others around them and gauge from their reactions the seriousness of a crisis (Arafat et al. 2020a, 2020b). From a psychological reactance theory perspective (Clee and Wicklund 1980), panic buying can be explained by the perceived need for a threatened object when the threat to product availability is experienced by consumers as a loss of control. It is often a self-fulfilling prophecy with the more that customers purchase impulsively and obsessively, the more anxiety consumers experience due to scarcity, and the more quickly products may get sold out (Islam et al. 2021). As such, panic buying is usually regarded as having both cognitive and affective aspects of non-normal consumer behavior.

Significantly, in terms of crisis and disaster management, panic buying is an expected response during disasters and crises as such events threaten both individual and society ability to cope with the unexpected and threatens the individual and social equilibrium (Arafat et al. 2020a, 2020b; Hall et al. 2020; Yuen et al. 2020). Indeed, Wordsworth et al. (2021) suggest that previous experience of disasters may predispose consumers to be better prepared and informed with respect to responding to new crises, including awareness of the items they may need to help get them through a disaster physically and psychologically. As such, some consumption which may be framed as panic buying by one set of researchers may be acknowledged as potentially rational and resilient by others (Hall et al. 2016; Kostev and Lauterbach 2020; Benker 2021; Wordsworth et al. 2021)

\subsection{Panic Buying and Consumption Displacement during COVID-19}

The burgeoning evidence on panic buying globally due to COVID-19 shows that stockpiling behavior of non-perishable food and bathroom products was not uncommon, with panic buying of toilet paper receiving considerable media publicity (Garbe et al. 2020; Kirk and Rifkin 2020; Loxton et al. 2020; Yoshizaki et al. 2020; Leung et al. 2021; Taylor 2021). Panic buying is part of the wider process of consumption displacement that occurs during disasters and pandemics. Consumption displacement refers to the shift in 
consumption that occurs when consumers experience a change in the usual availability of goods, services and amenities as the result of an external event, and which is characterized by the points in space and time where consumption occurs and by the movements to, from, and between those points (Hall et al. 2020). In other words, the when, where, what, why and how that characterizes consumption during non-routine consumption (Hall et al. 2020).

Chronopoulos et al. (2020) suggest that overall, United Kingdom consumers respond to negative shocks by reducing spending although panic buying does occur in some product categories. In Germany, a $126 \%$ and $137 \%$ increase in sales of canned fruits and vegetables were noted during March and the average sales of non-perishable goods remained above the average thereafter (Lehberger et al. 2021). In a Chinese study, Wang et al. (2020) showed that after the outbreak of COVID-19, consumers extended their food reserves from an average of 3.37 to 7.37 days and were willing to pay a premium of $60.5 \%$ on fresh product reserves. Both media and governments have contributed to fears about the scarcity of food and other services (Dubey et al. 2020; Cato et al. 2021). In Canada, overall sales were 46\% higher in grocery stores for the week ending 14 March in 2020 compared to 2019. In terms of specific grocery store product categories milk sales increased by $31 \%$, butter by $76 \%$ and fresh chicken by 50\% (Weersink et al. 2020).

However, there are substantial variations in the patterns of consumer expenditure during and between lockdowns both between and within countries. Spending is affected both by restrictions on consumer mobility and threats of impending government-imposed lockdowns (Chronopoulos et al. 2020; Hall et al. 2020; Kemp et al. 2021). Overall information regarding consumer response to pandemic interventions provides valuable short and long-term perspectives for government policy making during economic and health crises and also assists in disaster preparedness and management. This study therefore uses the daily collection and aggregation of transaction data from the retail sector to provide an assessment of the impact of COVID-19 on consumer spending and panic buying and consumption displacement within the context of longer-term expenditure patterns.

\section{Data and Findings}

To assess consumer purchasing behavior during the COVID-19 pandemic, retail spending and transactional data for different retail sectors for the period between January 2017 and December 2020 were sourced from Verisk New Zealand. This aligns with approaches used in previous studies (Wang et al. 2020). In the analysis, we limited data use to spending and transactional data by Christchurch residents in the Christchurch urban area and main retail type. Christchurch is New Zealand's second largest city and the largest urban center on New Zealand's South Island (Statistics New Zealand 2021). Annual retail sales in Christchurch amounted to NZD 5.4 billion in 2020, representing 9.1 percent of New Zealand's overall retail spending of NZD 59.5 billion.

\subsection{Overall Retail Spending Patterns}

Overall retail spending volume in New Zealand (NZ) Dollars since 2017 can be seen in Figure 1. Notable are the characteristic annual volume surges prior to Easter and Christmas holidays and their decline afterwards. The visible pre-Easter spikes signify amplified shopping volumes in preparation for mandatory shop closedowns on Good Friday and Easter Sunday, while trading volumes on Good Friday and Easter Sunday decline substantially due to such closures. Annual pre-Christmas shopping patterns include a steady rise of volumes, culminating in a peak on the day prior to Christmas. This is followed by a sharp drop on Christmas day, which is also due to mandatory closures of most retailers on Christmas day. Retail shopping volume patterns regarding Christmas and Easter repeat consistently in the first three years of the observation period, with only minor variations in magnitude. 


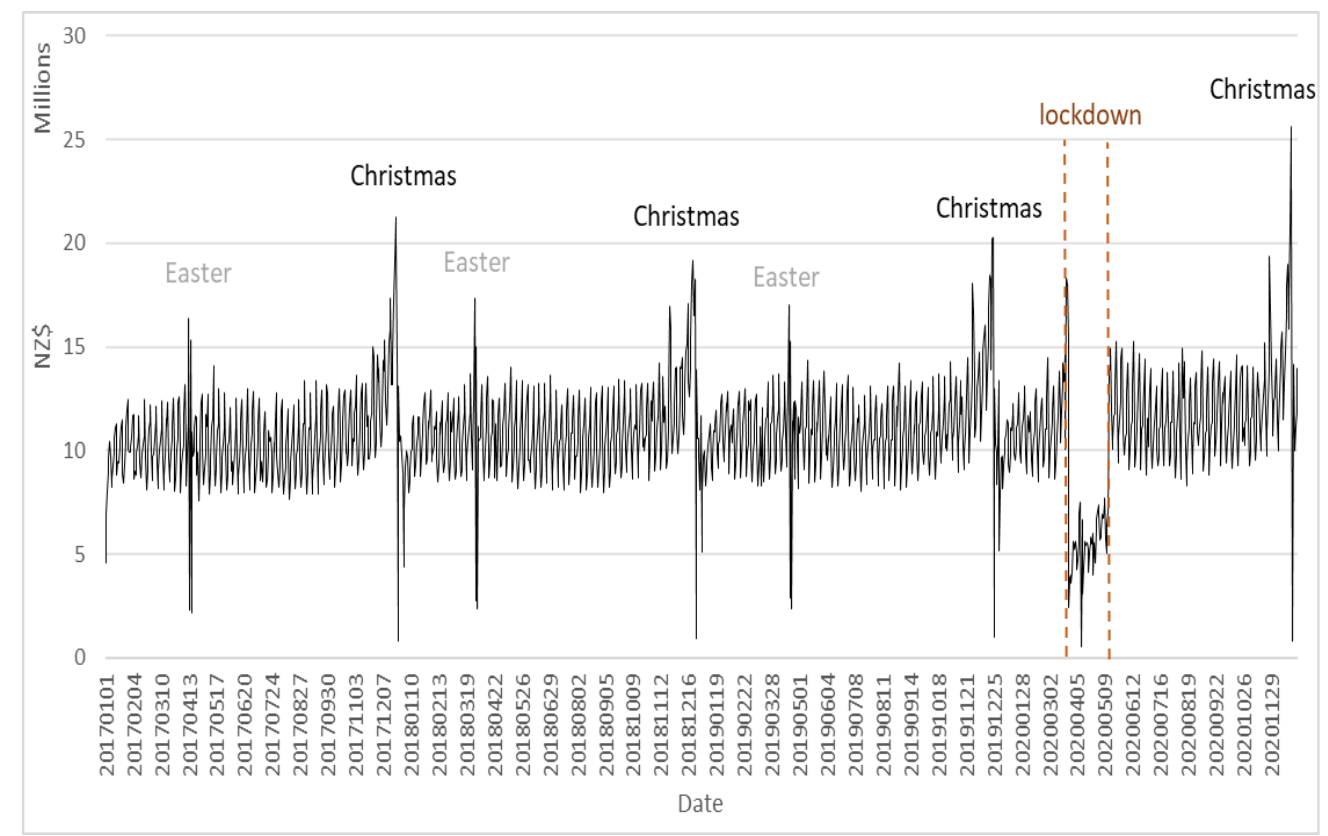

Figure 1. Daily retail spending, Christchurch residents, 2017-2020. Source. Authors, (Verisk New Zealand 2021).

The COVID 19 crisis started to emerge in China in late 2019 (Hall et al. 2020); however, the developing pandemic became publicly relevant in New Zealand only as its implications via potentially infected tourists arriving in the country became apparent (see Figure 2 refer to timeline graph). Overall retail spending in early 2020 thus exhibited the pattern that would normally be expected.

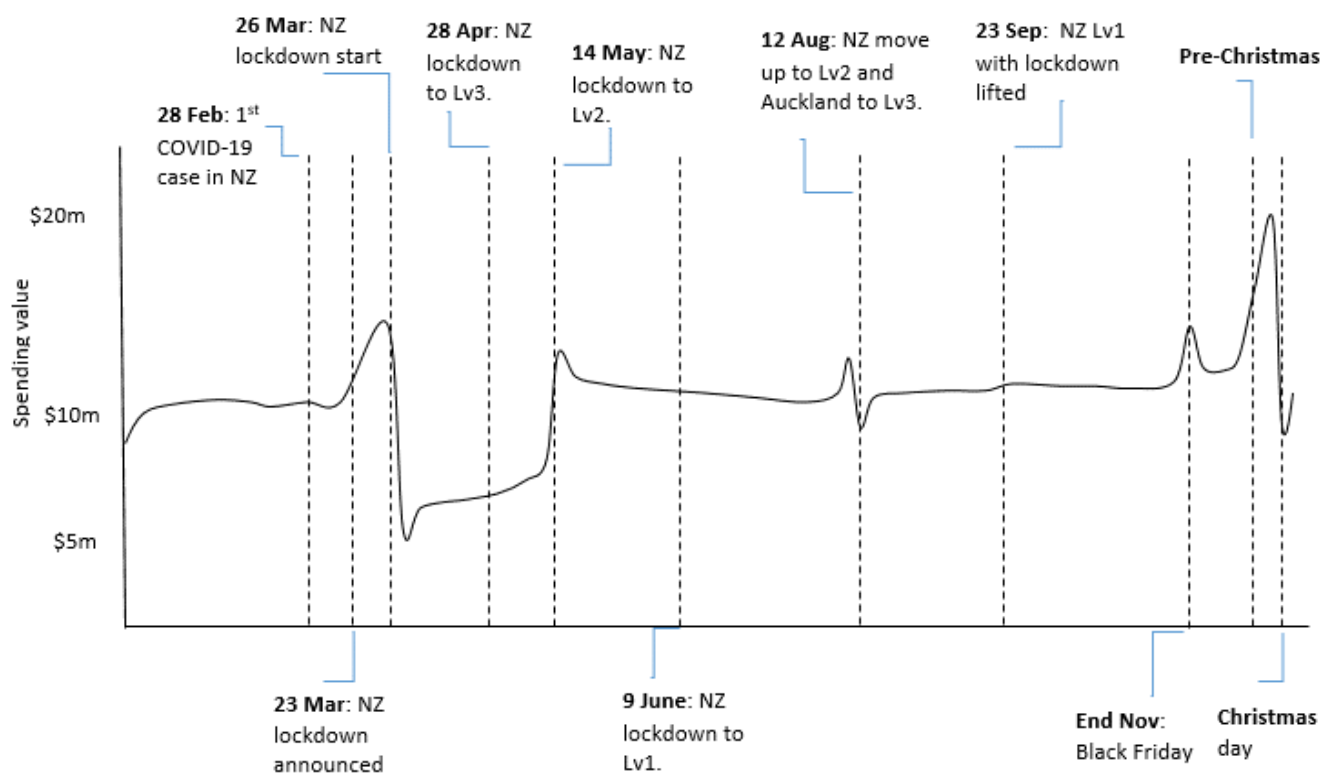

Figure 2. Timeline of COVID-19 in New Zealand and Christchurch retail spending, 2020. Source. Authors; (Verisk New Zealand 2021).

As worldwide media coverage of the spread of COVID-19 grew and local cases began to be reported, the New Zealand government announced and introduced various alert levels with measures in response to the pandemic (Table 1). On 23 March 2020, the government announced that the strictest lockdown level, Level 4, will apply from 26 March for the entire country. This resulted in an immediate increase in consumer spending in the 
days leading up to the 26 (Gerritsen et al. 2020). As the alert levels changed from April, consumers reacted positively as the spending lifted and by 14 May, most restrictions were removed and retail spending remained high. On 13 August 2020, new community cases of COVID-19 forced another change in alert levels, with Auckland moving back to level 3 and the rest of New Zealand to level 2. This announcement again led to a drastic change in consumer purchases, even within Christchurch. Spending stabilized thereafter and the lifting of the lockdowns in September, coupled with Black Friday sales and the Christmas period saw spending grow for the remainder of the year.

Table 1. Alert levels, risk assessment and measures.

\begin{tabular}{ccc}
\hline Alert Level & Risk Assessment & Measures Applied That Affect Consumption \\
\hline & & Border entry measures to minimize risk of importing COVID-19 cases \\
Alert Level 1 & Isolated household & Self-isolation and quarantine required if sick \\
Prepare & transmission could be & Schools and workplaces open \\
Disease contained & occurring in New Zealand & Physical distancing encouraged \\
& & No restrictions on gatherings \\
& & No restrictions on domestic transport \\
\hline
\end{tabular}

People can be with friends and family, go shopping, or travel domestically, but should follow public health guidance

Physical distancing of two meters, with one meter physical distancing in controlled environments like workplaces unless other measures are in

Alert Level 2

Reduce

Disease is contained, but risk of community transmission remains
Household transmission could be occurring Single or isolated cluster outbreaks place

No more than 100 people at indoor or outdoor gatherings

Sport and recreation activities are allowed subject to conditions, contact tracing and physical distancing

Public venues must comply with public health measures

Businesses open to the public, but must follow public health guidance including in relation to physical distancing and contact tracing Alternative ways of working encouraged Educational facilities open

People instructed to stay home in their bubble other than for essential personal movement

Physical distancing of two meters outside home including on public transport, or one meter in controlled environments like schools and workplaces

Bubbles must stay within their immediate household bubble, but can expand to connect with close family, bring in caregivers, or support isolated people. This extended bubble should remain exclusive

People must work from home unless that is not possible

Businesses can open premises, but cannot physically interact with customers

Low-risk local recreation activities are allowed

Public venues are closed (libraries, museums, cinemas, food courts, gyms, pools, playgrounds, markets)

Gatherings of up to ten people are only allowed for weddings and funerals

Inter-regional travel is highly limited to essential workers, with limited exemptions

People instructed to stay at home in their bubble other than for essential personal movement
Alert Level $4 \quad$ Community transmission Lockdown

Likely that disease is not contained is occurring

Widespread outbreaks and new clusters activity is allowed in the local area

Safe recreational activity is allowed in
Travel is severely limited

All gatherings cancelled and all public venues closed

Businesses closed except for essential services, e.g., supermarkets, pharmacies, clinics, petrol stations and lifeline utilities Educational facilities closed

Rationing of supplies and requisitioning of facilities possible 
The total retail spending in Figure 1 consists of six sub-types of retail namely (i) apparel and personal, (ii) cafes, restaurants, bars and takeaways, (iii) fuel and automotive, (iv) groceries and liquor, (v) home and recreation and (vi) other consumer retail. We consider the spending behavior from consumers on the two largest sub-types, namely groceries and liquor and home and recreational purchases in our analysis. Combined they contribute 67 percent of total retail spending in the city for 2020. Figure 3 shows the cyclical nature of consumer purchase trends for the selected retail types during 2019 and 2020.

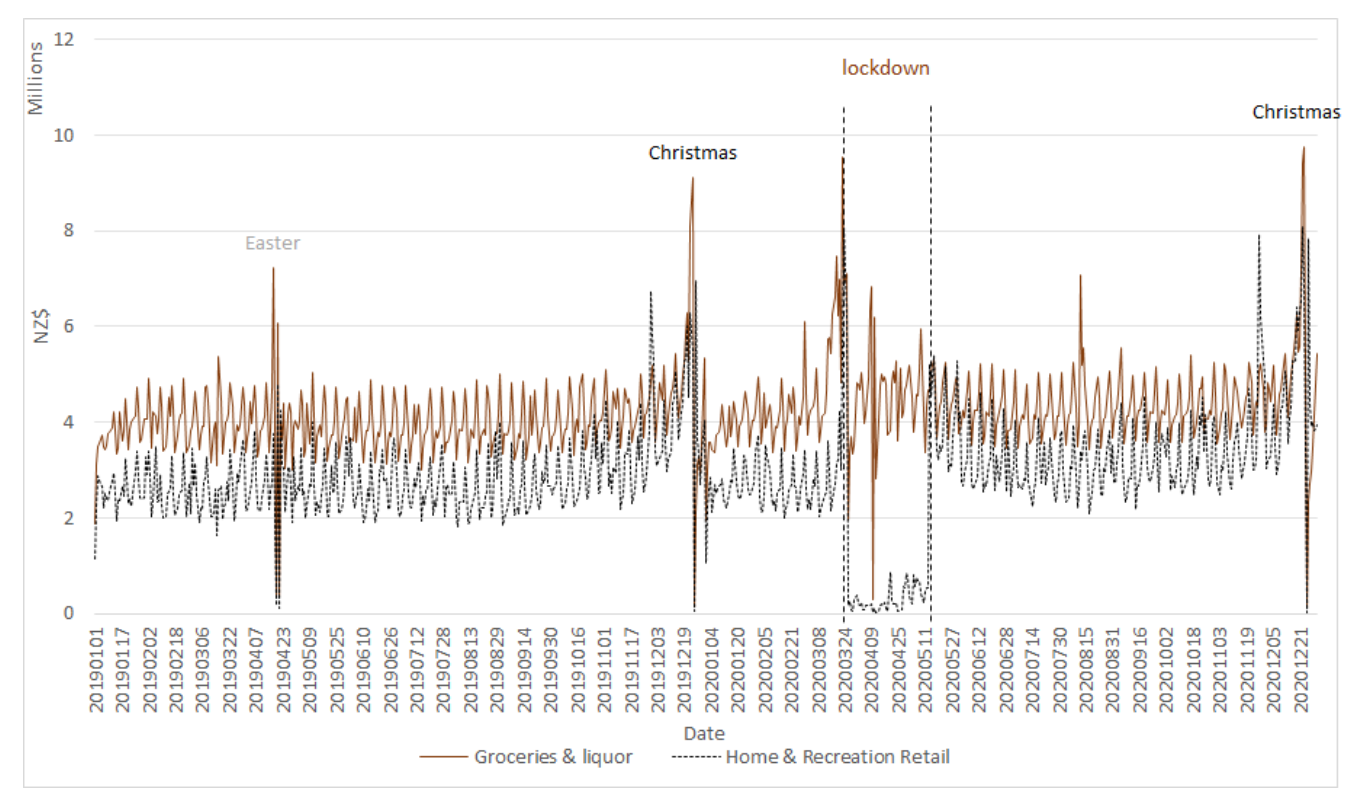

Figure 3. Daily spending per retail type, Christchurch residents, 2019-2020. Source. Authors; (Verisk New Zealand 2021).

The seasonal spending in both retail types mirrors the total retail spending, with a surge prior Easter and Christmas in 2019. During the level 4 lockdown, spending trends decouple for these retail types, as groceries and liquor remain high, while home and recreational spending reduce to almost zero. The difference cannot be more obvious during the level 4 lockdown period and once lockdown ends mid-May, we observe a recoupling of the trend. This change was as a result of the impositions and withdrawal of restrictions placed on activities considered to be non-essential.

At this point, the data suggest that surges in spending do occur annually at specific periods within the year, most notably Easter and Christmas. The period leading-up to lockdown, and more precisely the grace period provided by government from the day where the lockdown is announced up and to the day the lockdown is implemented, reflect a similar surge in spending. This surge in spending is a deviation from the norm.

Analysis of the standard deviation of the same data and retail types over the period 2018 to 2020 reveal the extent of the surge as a result of the lockdown. The trend beyond one standard deviation in spending for home and recreation (left) and groceries and liquor (right) is shown in Figure 4.

The daily standard deviation is calculated from the preceding 7-day moving average. This captures daily and weekly seasonality within the spending data and allows for comparison of spending over time. The results reveal relatively stable deviation at one deviation above the average, throughout the year, however, the effect of Christmas and Easter spending is still visible in the data (see Figure 4). The weeks following the closure of business at Easter and Christmas reveal significant variation due to the lower 7-day average for the week in which the comparison is provided. 

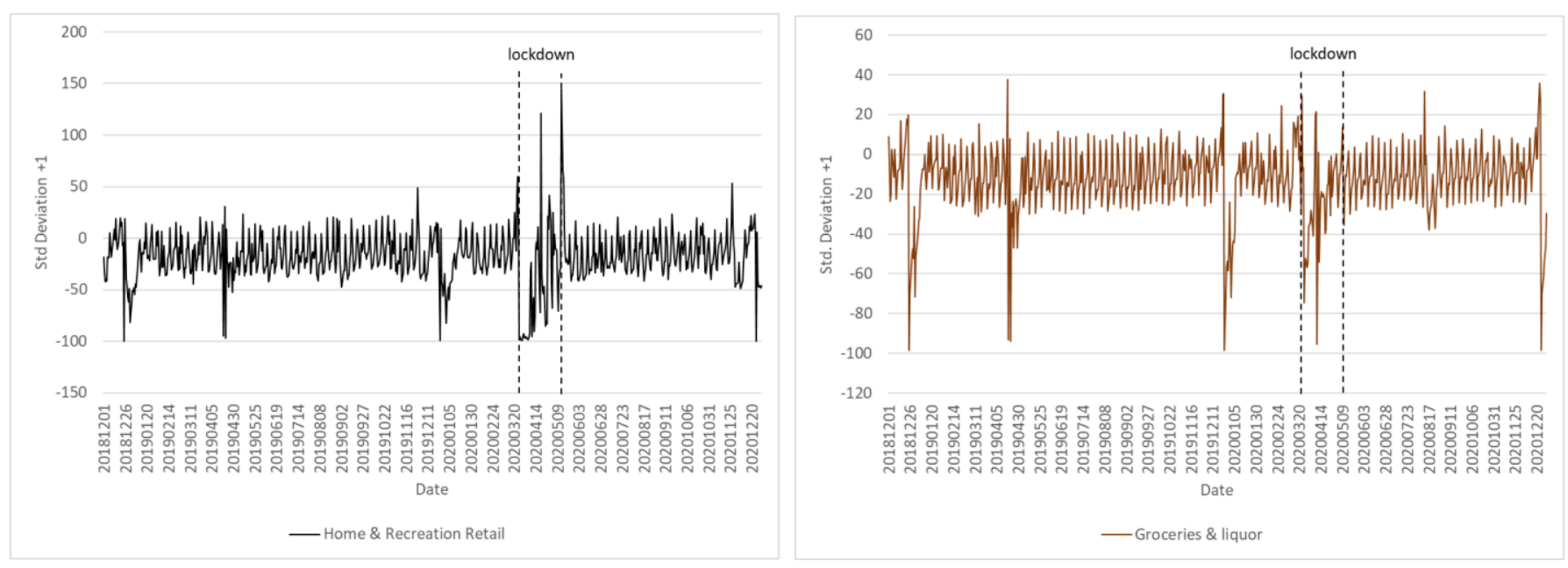

Figure 4. Std. Deviation +1, daily spending per transaction, Christchurch residents, 2018-2020. Source. Authors; (Verisk New Zealand 2021).

The deviation reveals that the initial lockdown in March and consequent spending surge is similar and within the same upper boundary to that experienced during Christmas and Easter. Furthermore, the lockdown announcement in August of 2020 and a move up the alert levels (Alert Level 3 for Auckland and 2 for the rest of New Zealand) had a similar immediate spike in the deviation in groceries and liquor. The deviation for home and recreational retail reveal two spikes within the lockdown period, one on 20 April, which does not relate to any government announcement and therefore likely due to essential service activity. The other instance with a spike in the deviation is on 14 May, the first day back down to Alert Level 2 where movement restrictions was lifted.

\subsection{Transactions}

The volume of transactions provides a further indication of consumer behavior. A combination of transactions and retail value reveal the spending value per transaction. We therefore postulate that during periods of increasing retail spending, such as Christmas and Easter, the value per transaction will be higher. The seasonal trend suggest that retailers will be prepared to accommodate this surge in spending by ensuring their value chain and logistics network based on just-in-time manufacturing and delivery is capable of supporting this short, but expected surge (Hobbs 2020).

We test this by estimating the daily spending value per transaction for each of the retail types. Figure 5 shows the daily spending value per transaction for groceries and liquor and home and recreational services from 2019 to 2020.

It is apparent that groceries and liquor values per transaction were very consistent throughout 2019 and exhibited minor breakouts only around Easter and Christmas. In 2020 a rapid rise in transaction value is evident from around mid-March as news from international lockdowns of countries started to emerge and continued to increase daily when the implementation of a lockdown became foreseeable. Due to the continued accessibility of grocery stores panic buying continued into the lockdown and began to subside slowly after the Easter weekend until it stabilized after the lockdown. Even then, a post lockdown level shift is clearly noticeable that continued until the onset of Christmas shopping toward the end of 2020.

The results reveal, quite clearly, that the surge in spending did not stop when lockdown took effect, in-fact, and consumers continued to spend more per transaction within the lockdown period.

Inflation, measured as a bundle of goods that consumers typically buy, remained low during the March and June quarters of 2020 at $2.5 \%$ and $1.5 \%$, respectively (Reserve Bank of New Zealand 2021). Although, substitution of certain goods that were in limited supply 
likely took place, the overall indication is that prices did not increase rapidly within this period that affected the increase in spending values. Rather, the behavior of consumers appears to have been the main driving force.

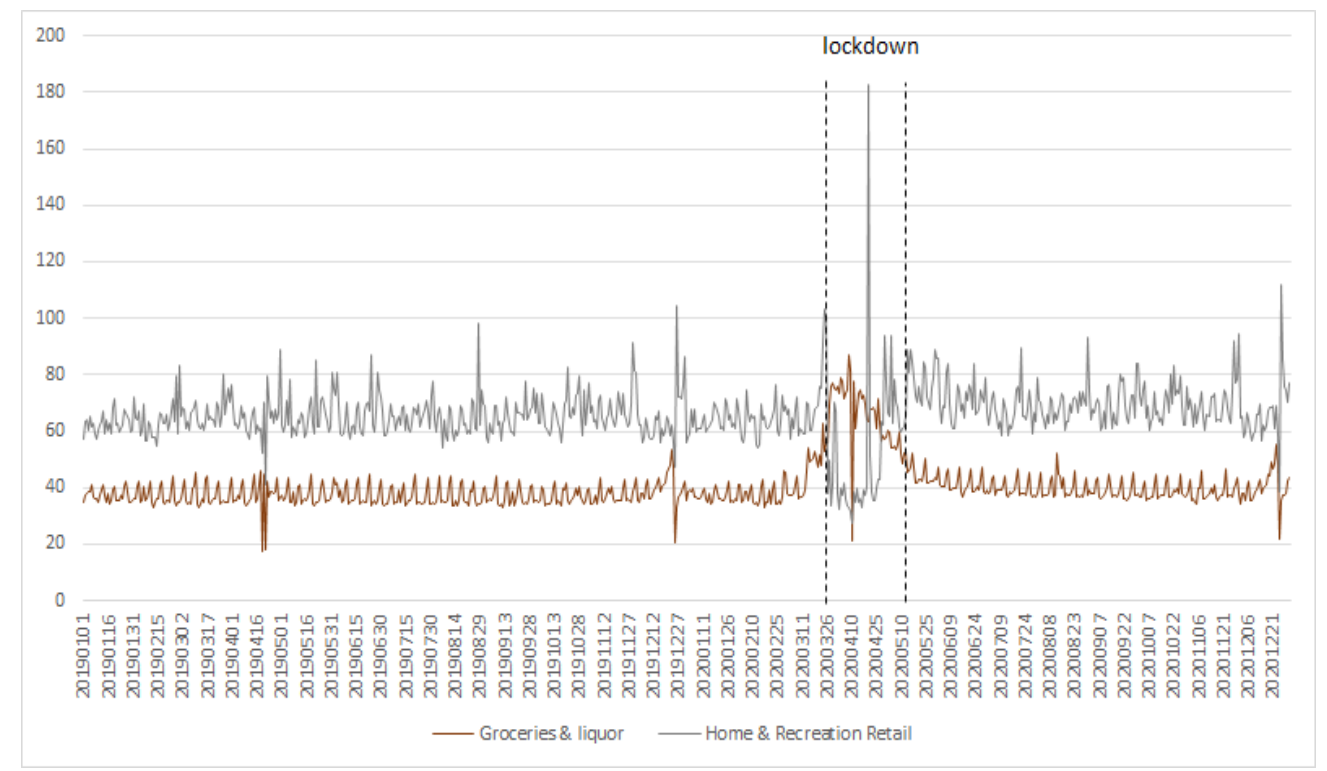

Figure 5. Daily spending per transaction, Christchurch residents, 2019-2020. Source. Authors; (Verisk New Zealand 2021).

\section{Discussion}

The patterns evident from the empirical analysis of data for the city of Christchurch reveal several characteristics that appear associated with lockdown-related panic buying:

1. The panic buying event is catalyzed by an unexpected and suddenly occurring crisis phenomenon that triggers a policy response (e.g., a partial or complete lockdown) which may impact on people's livelihood and their potential inability to provide for themselves in light of a prolonged crisis scenario.

2. Once a panic buying scenario is initiated, overall spending increases sharply in the lead up to anticipated lockdowns.

3. Transactional spending increases and subsides only slowly to a level higher than pre lockdown.

4. Different consumption categories exhibit vastly different patterns. Consumption displacement occurs as increased spending flows from non-essentials to necessities of life. This is exacerbated by hoarding of essential items and government mandated shutdowns of some non-essential retail sectors.

5. The magnitude of the panic buying event far exceeds historical seasonal patterns of consumer spending (outside of Christmas and Easter).

The Christchurch regional results regarding the relationship between COVID-19 lockdowns and consumer expenditure provide significant insights into panic buying and hoarding behavior. The results illustrate the changes in consumption displacement that occur over the life course of a crisis (Hall et al. 2020). The New Zealand experience of panic buying and hoarding behavior in the period prior to the imposition of lockdowns is similar to that of overseas (Garbe et al. 2020; Kirk and Rifkin 2020; Loxton et al. 2020; Yoshizaki et al. 2020; Leung et al. 2021; Taylor 2021). However, the overall longer-term pattern of expenditure during the pandemic is different from that experienced by several European countries which suggested that consumers reduce their expenditure as a response "to negative shocks increased uncertainty, financial constraints or declining expectations regarding future income prospects" (Chronopoulos et al. 2020, p. 151). This may well be correct in those countries with frequent lockdowns, but the present results suggest that 
while consumers share common characteristics of panic buying and hoarding at the onset of a disaster, the understanding of consumer responses over the longer term needs to be more nuanced with respect to the nature and management of the disaster as well as the time period examined. Much of the UK and European experience (Chronopoulos et al. 2020 ) is of nations that experienced multiple major lockdowns. In contrast, the greater Christchurch region and most of New Zealand only experienced one severe extended lockdown leading to substantially different consumer behavior and confidence over the longer-term compared to international counterparts even when COVID management and alert levels were altered to respond to localized outbreaks (Hunt 2021).

From a theoretical perspective, similar to other studies (Dholakia 2020; Yuen et al. 2020), we argue that panic buying is non-routine consumption behavior that is driven by the psychological need to self-protect in relation to an external event (disasters and pandemics). Consumers hoard both essential and non-essential items in anticipation of the limited availability of these items in the short-term and even long-term depending on the scale, magnitude and duration of the disruptive event. In essence, the consumption displacement that occurs as a result of a disruptive event represents a coping mechanism for individuals (Arafat et al. 2020a, 2020b). Of interest, given that groceries and liquor sales exhibited panic buying behavior, have implications for how individuals cope with uncertainty and drinking behavior, in particular, could have long-term impact on individual and community wellbeing. The increase in home and recreation product sales indeed reflect individuals' need to undertake activities that keep them busy during and post-lockdown, highlighting perhaps another coping mechanism that is activated in response to COVID-19. A focus on self, from a psychological perspective, but also on self-possessions (material things, e.g., house) confirm that humans tend to self-protect during uncertain times.

\section{Conclusions}

This study has provided an examination of COVID-19-related panic buying and hoarding behavior within the context of longer-term consumption patterns for the greater Christchurch region of New Zealand. The results illustrate that the region shares similar panic buying and hoarding behavior at the onset of the imposition of substantial COVID19-related mobility and social distancing restrictions (lockdown) but that longer term consumer expenditure is more positive than many European nations that have experienced multiple lockdowns. Reasons for this are potentially related to New Zealand's wider success in combating COVID-19 and the relatively short period of lockdown over the pandemic period. Another possible explanation, which deserves further study in a wider context, is that the region's previous experience with recovery from the impacts of a severe earthquake sequence may have meant that consumers were more experienced in dealing with disasters and their aftermath (Hall et al. 2016). Indeed, the large majority of studies of consumer hoarding tend to describe it in terms of panicked behavior without sufficient consideration of either the prior experiences of consumers with disasters and the retail and supply chain issues they create or the potential rationality and value of such an approach in some circumstances (Kostev and Lauterbach 2020). This is a significant point as behaviors that are often portrayed in a negative light may actually be a significant contributing factor to the increased resilience of individuals and households to external shock (Benker 2021). In addition, it is worth noting that hoarding behavior by businesses is seemingly ignored in research on panic buying and presents a significant research opportunity given the way in which it intersects with consumer purchasing and supply chain stress (Hall et al. 2020; Remko 2020).

The other dimension of the study that is of considerable importance in the broader context of understanding the economic behavior of consumers during crises and disasters is positioning COVID-19 panic buying prior to lockdown in a longitudinal context. Although COVID-19 panic buying clearly represents a form of consumption displacement (Hall et al. 2020) with respect to regular purchasing patterns and the imposition of restrictions on mobility and social distancing creates considerable turbulence and shifts in consumption 
in the consumer ecosystem, it is noticeable that daily retail spend is little different from other peaks at Christmas, Easter and Black Friday. This finding suggests that researchers need to better examine crisis- and disaster-related panic buying in comparison with the consumer behaviors and expenditure related to major regular consumption events for a better understanding of such behaviors, including concerns over stockout (Ma et al. 2018; Kumar et al. 2021) and the various meanings associated with consumption (Tynan and McKechnie 2009; Veer et al. 2016). Indeed, in seeking to differentiate panic buying from other consumption events, it is clear that using the volume of sales alone is not adequate. Instead, we would advocate that any adequate economic definition of panic buying needs to recognize it in terms of the non-normal daily spending value per retail transaction of a given population. The conclusions of this study are, of course, only drawn from the one location that limits the potential applicability of the findings. The data do not reveal the effect of (food) waste associated with existing spending in particular for groceries that triggers a follow-up transaction. This could potentially explain the gradual increase in grocery spending over time during lockdown. The transactional data group all sales into the main retail sector and do not distinguish between spending on consumer goods, in particular the transactions on non-durable goods that could provide further insight into value-chain pressures during panic buying and stockpiling. Nevertheless, this study appropriately suggests that the study of panic buying requires that considerably more attention be given to the peculiarities of consumption displacement in terms of appropriate understanding of the crisis and location, both in a comparative context and over time.

Author Contributions: Conceptualization, C.M.H., P.F., G.P., D.D.; methodology, C.M.H., P.F., G.P., D.D.; software, P.F., D.D.; formal analysis, P.F., D.D.; data curation, P.F.; writing-original draft preparation, C.M.H., P.F., G.P., D.D.; writing—review and editing, C.M.H., G.P.; visualization, P.F. All authors have read and agreed to the published version of the manuscript.

Funding: This research received no external funding.

Data Availability Statement: The data presented in this study are available on request from the corresponding author. The data are not publicly available due to its commercial nature.

Conflicts of Interest: The authors declare no conflict of interest.

\section{References}

Arafat, S. M. Yasir, Sujita Kumar Kar, Marthoenis Marthoenis, Pawan Sharma, Ehsanul Hoque Apu, and Russell Kabir. 2020a. Psychological underpinning of panic buying during pandemic (COVID-19). Psychiatry Research 289: 113061. [CrossRef]

Arafat, S. M. Yasir, Sujita Kumar Kar, Vikas Menon, Charanya Kaliamoorthy, Srijeeta Mukherjee, Angi Alradie-Mohamed, Pawan Sharma, Marthoenis Marthoenis, and Russell Kabir. 2020b. Panic buying: An insight from the content analysis of media reports during COVID-19 pandemic. Neurology, Psychiatry and Brain Research 37: 100-3. [CrossRef] [PubMed]

Ballantine, Paul W., Shazia Zafar, and Andrew G. Parsons. 2014. Changes in retail shopping behaviour in the aftermath of an earthquake. The International Review of Retail, Distribution and Consumer Research 24: 1-13. [CrossRef]

Benker, Beth. 2021. Stockpiling as resilience: Defending and contextualising extra food procurement during lockdown. Appetite 156: 104981. [CrossRef]

Bonneux, Luc, and Wim Van Damme. 2006. An iatrogenic pandemic of panic. BMJ 332: 786-88. [CrossRef] [PubMed]

Brandtner, Patrick, Farzaneh Darbanian, Taha Falatouri, and Chibuzor Udokwu. 2021. Impact of COVID-19 on the customer end of retail supply chains: A big data analysis of consumer satisfaction. Sustainability 13: 1464. [CrossRef]

Bristow, Gillian. 2010. Resilient regions: Re-'place'ing regional competitiveness. Cambridge Journal of Regions, Economy and Society 3: 153-67. [CrossRef]

Cato, Susumu, Takashi Iida, Kenji Ishida, Asei Ito, Hiroto Katsumata, Kenneth Mori McElwain, and Masahiro Shoji. 2021. The bright and dark sides of social media usage during the COVID-19 pandemic: Survey evidence from Japan. International Journal of Disaster Risk Reduction 54: 102034. [CrossRef]

Chronopoulos, Dimitris K., Marcel Lukas, and John O. S. Wilson. 2020. Consumer spending responses to the Covid-19 pandemic: An assessment of Great Britain. Covid Economics 34: 145-86. [CrossRef]

Chu, Charlene K. 2018. Psychological ownership in hoarding. In Psychological Ownership and Consumer Behavior. Edited by Joann Peck and Suzanne B. Shu. Cham: Springer, pp. 135-44.

Clee, Mona A., and Robert A. Wicklund. 1980. Consumer behavior and psychological reactance. Journal of Consumer Research 6: $389-405$. [CrossRef] 
Coles, Eve, and Philip Buckle. 2004. Developing community resilience as a foundation for effective disaster recovery. Australian Journal of Emergency Management 19: 6-15.

Dholakia. 2020. Why Are We Panic Buying during the Coronavirus Pandemic. Available online: https://www.psychologytoday.com/ blog/the-science-behindbehavior/202003/why-are-we-panic-buying-during-the-coronavirus-pandemic (accessed on 1 March 2021).

Dubey, Souvik, Payel Biswas, Ritwik Ghosh, Subhankar Chatterjee, Mahua Jana Dubey, Subham Chatterjee, Durjoy Lahiri, and Carl J. Lavie. 2020. Psychosocial impact of COVID-19. Diabetes \& Metabolic Syndrome: Clinical Research E Reviews 14: 779-88. [CrossRef]

Garbe, Lisa, Richard Rau, and Theo Toppe. 2020. Influence of perceived threat of Covid-19 and HEXACO personality traits on toilet paper stockpiling. PLoS ONE 15: e0234232. [CrossRef] [PubMed]

Gerritsen, Sarah, Victoria Egli, Rajshri Roy, Jill Haszard, Charlotte De Backer, Lauranna Teunissen, Isabelle Cuykx, Paulien Decorte, Sara Pabian Pabian, Kathleen Van Royen, and et al. 2020. Seven weeks of home-cooked meals: Changes to New Zealanders' grocery shopping, cooking and eating during the COVID-19 lockdown. Journal of the Royal Society of New Zealand 17: 1-9. [CrossRef]

Government of New Zealand. 2020. New Zealand COVID-19 Alert Levels Summary. Available online: https://covid19.govt.nz/ assets / resources/tables/COVID-19-alert-levels-summary.pdf (accessed on 1 March 2021).

Hall, C. Michael, Sanna Malinen, Rob Vosslamber, and Russell Wordsworth, eds. 2016. Business and Post-Disaster Management: Business, Organisational and Consumer Resilience and the Christchurch Earthquakes. Abingdon: Routledge.

Hall, Michael C., Girish Prayag, Peter Fieger, and David Dyason. 2020. Beyond panic buying: Consumption displacement and COVID-19. Journal of Service Management 32: 113-28. [CrossRef]

Herjanto, Halimin, Muslim Amin, and Elizabeth F. Purington. 2021. Panic buying: The effect of thinking style and situational ambiguity. Journal of Retailing and Consumer Services 60: 102455. [CrossRef]

Hobbs, Jill E. 2020. Food supply chains during the COVID-19 pandemic. Canadian Journal of Agricultural Economics/Revue canadienne d'agroeconomie 68: 171-76. [CrossRef]

Hunt, Elle. 2021. Words matter: How New Zealand's clear messaging helped beat Covid. The Guardian. February 26. Available online: https:/ / www.theguardian.com/world/2021/feb/26/words-matter-how-new-zealands-clear-messaging-helped-beatcovid (accessed on 1 March 2021).

Islam, Tahir, Abdul Hameed Pitafi, Vikas Arya, Ying Wang, Naeem Akhtar, Shujaat Mubarik, and Liang Xiaobei. 2021. Panic buying in the COVID-19 pandemic: A multi-country examination. Journal of Retailing and Consumer Services 59: 102357. [CrossRef]

Karatzias, Thanos, Sally Jowett, Elsie Yan, Robert Raeside, and Ruth Howard. 2017. Depression and resilience mediate the relationship between traumatic life events and ill physical health: Results from a population study. Psychology, Health \& Medicine 22: 1021-31. [CrossRef]

Kemp, Elyria, My Myla Bui, and McDowell Porter III. 2021. Preparing for a crisis: Examining the influence of fear and anxiety on consumption and compliance. Journal of Consumer Marketing. in press. [CrossRef]

Khan, Himayatullah, Laura Giurca Vasilescu, and Asmatullah Khan. 2008. Disaster management cycle-a theoretical approach. Journal of Management and Marketing 6: 43-50.

Kirk, Colleen P., and Laura S. Rifkin. 2020. I'll trade you diamonds for toilet paper: Consumer reacting, coping and adapting behaviors in the COVID-19 pandemic. Journal of Business Research 117: 124-31. [CrossRef]

Kostev, Karel, and Silke Lauterbach. 2020. Panic buying or good adherence? Increased pharmacy purchases of drugs from wholesalers in the last week prior to Covid-19 lockdown. Journal of Psychiatric Research 130: 19-21. [CrossRef] [PubMed]

Kowal, Marta, Tao Coll-Martín, Gözde Ikizer, Jesper Rasmussen, Kristina Eichel, Anna Studzińska, Karolina Koszałkowska, Maciej Karwowski, Arooj Najmussaqib, Daniel Pankowski, and et al. 2020. Who is the most stressed during the COVID-19 pandemic? Data from 26 countries and areas. Applied Psychology: Health and Well-Being 12: 946-66. [CrossRef] [PubMed]

Kumar, Madhumitha Ezhil, Dheeraj P. Sharma, and Archit V. Tapar. 2021. Out-of-stock justifications and consumers' behavioral outcomes-exploring the role of product type and sales level information in out-of-stock situations. Journal of Retailing and Consumer Services 60: 102458. [CrossRef]

Lehberger, Mira, Anne-Katrin Kleih, and Kai Sparke. 2021. Panic buying in times of coronavirus (COVID-19): Extending the theory of planned behavior to understand the stockpiling of nonperishable food in Germany. Appetite 161: 105118. [CrossRef]

Leung, Janni, Jack Yiu Chak Chung, Calvert Tisdale, Vivian Chiu, Carmen C. W. Lim, and Gary Chan. 2021. Anxiety and panic buying behaviour during COVID-19 pandemic-A qualitative analysis of toilet paper hoarding contents on Twitter. International Journal of Environmental Research and Public Health 18: 1127. [CrossRef]

Lopes, Barbara, Catherine Bortolon, and Rusi Jaspal. 2020. Paranoia, hallucinations and compulsive buying during the early phase of the COVID-19 outbreak in the United Kingdom: A preliminary experimental study. Psychiatry Research 293: 113455. [CrossRef] [PubMed]

Loxton, Mary, Robert Truskett, Brigitte Scarf, Laura Sindone, George Baldry, and Yinong Zhao. 2020. Consumer behaviour during crises: Preliminary research on how coronavirus has manifested consumer panic buying, herd mentality, changing discretionary spending and the role of the media in influencing behaviour. Journal of Risk and Financial Management 13: 166. [CrossRef]

$\mathrm{Ma}$, Ke, Tong Chen, and Chundong Zheng. 2018. Influence of thinking style and attribution on consumer response to online stockouts. Journal of Retailing and Consumer Services 43: 218-25. [CrossRef]

Michie, Susan, and Robert West. 2020. Behavioural, environmental, social, and systems interventions against covid-19. BMJ 370: 1-2. [CrossRef] 
Modica, Marco, and Aura Reggiani. 2015. Spatial economic resilience: Overview and perspectives. Networks and Spatial Economics 15: 211-33. [CrossRef]

Mukhtar, Sonia. 2020. Psychological health during the coronavirus disease 2019 pandemic outbreak. International Journal of Social Psychiatry 66: 512-16. [CrossRef] [PubMed]

Naeem, Muhammad. 2020. Understanding the customer psychology of impulse buying during COVID-19 pandemic: Implications for retailers. International Journal of Retail \& Distribution Management 49: 377-93. [CrossRef]

Perry, Ronald W., and Michael K. Lindell. 2003. Understanding citizen response to disasters with implications for terrorism. Journal of Contingencies and Crisis Management 11: 49-60. [CrossRef]

Qian, Da, and Ou Li. 2020. The relationship between risk event involvement and risk perception during the COVID-19 outbreak in China. Applied Psychology: Health and Well-Being 12: 983-99. [CrossRef]

Rahmi, Rahmi, Hideo Joho, and Tetsuya Shirai. 2019. An analysis of natural disaster-related information-seeking behavior using temporal stages. Journal of the Association for Information Science and Technology 70: 715-28. [CrossRef]

Remko, Van Hoek. 2020. Research opportunities for a more resilient post-COVID-19 supply chain-Closing the gap between research findings and industry practice. International Journal of Operations \& Production Management 40: 341-55. [CrossRef]

Reserve Bank of New Zealand. 2021. Inflation. Available online: https:/ / www.rbnz.govt.nz/statistics/key-graphs/key-graph-inflation (accessed on 18 February 2021).

Slovic, Paul. 1987. Perception of risk. Science 236: 280-85. [CrossRef] [PubMed]

Song, Shuang, Jenson C. L. Goh, and Hugh T. W. Tan. 2021. Is food security an illusion for cities? A system dynamics approach to assess disturbance in the urban food supply chain during pandemics. Agricultural Systems 189: 103045. [CrossRef]

Statistics New Zealand. 2021. Functional Urban Areas-Methodology and Classification; Wellington: Statistics New Zealand. Available online: https:/ / www.stats.govt.nz/methods/functional-urban-areas-methodology-and-classification (accessed on 1 March 2021).

Tan, Yuxin, Xiuyun Lin, Dazhou Wu, Hui Chen, Yongqiang Jiang, Ting He, Jinxiu Yin, and Yingying Tang. 2020. Different trajectories of panic and the associated factors among unmarried Chinese during the COVID-19 pandemic. Applied Psychology: Health and Well-Being 12: 967-82. [CrossRef] [PubMed]

Taylor, Steven. 2021. Understanding and managing pandemic-related panic buying. Journal of Anxiety Disorders 70: 102364. [CrossRef]

Tsao, Yu-Chung, Praveen Vijaya Raj Pushpa Raj, and Vincent Yu. 2019. Product substitution in different weights and brands considering customer segmentation and panic buying behavior. Industrial Marketing Management 77: 209-20. [CrossRef]

Tynan, Caroline, and Sally McKechnie. 2009. Hedonic meaning creation though Christmas consumption: A review and model. Journal of Customer Behaviour 8: 237-55. [CrossRef]

Van Bavel, Jay J., Katherine Baicker, Paulo S. Boggio, Valerio Capraro, Aleksandra Cichocka, Mina Cikara, Molly J. Crockett, Alia J. Crum, Karen M. Douglas, James N. Druckman, and et al. 2020. Using social and behavioural science to support COVID-19 pandemic response. Nature Human Behaviour 4: 460-71. [CrossRef] [PubMed]

Veer, Ekant, Lucie K. Ozanne, and C. Michael Hall. 2016. Sharing cathartic stories online: The internet as a means of expression following a crisis event. Journal of Consumer Behaviour 15: 314-24. [CrossRef]

Verisk New Zealand. 2021. "From Spending to Strategy". Available online: https://marketview.co.nz/solutions / (accessed on 1 March 2021).

Wang, Erpeng, Ning An, Zhifeng Gao, Emmanuel Kiprop, and Xianhui Geng. 2020. Consumer food stockpiling behavior and willingness to pay for food reserves in COVID-19. Food Security 12: 739-47. [CrossRef]

Wang, H. Holly, and Na Hao. 2020. Panic buying? Food hoarding during the pandemic period with city lockdown. Journal of Integrative Agriculture 19: 2916-25. [CrossRef]

Weersink, Alfons, Mike von Massow, and Brendan McDougall. 2020. Economic thoughts on the potential implications of COVID-19 on the Canadian dairy and poultry sectors. Canadian Journal of Agricultural Economics/Revue canadienne d'agroeconomie 68: 195-200. [CrossRef]

Wordsworth, Russell, C. Michael Hall, Girish Prayag, and Sanna Malinen. 2021. Critical perspectives on disaster and crisis research: Revealing and responding to vulnerability. In Research Methodology in Strategy and Management. Edited by Aaron Hill, Aaron McKenny, Paula O'Kane and Sotirios Paroutis. Cheltenham: Emerald Publishing.

Yang, Zhixu, and Ziqiang Xin. 2020. Heterogeneous risk perception amid the outbreak of COVID-19 in China: Implications for economic confidence. Applied Psychology: Health and Well-Being 12: 1000-18. [CrossRef]

Ye, Zhi, Xueying Yang, Chengbo Zeng, Yuyan Wang, Zijiao Shen, Xiaoming Li, and Danhua Lin. 2020. Resilience, social support, and coping as mediators between COVID-19-related stressful experiences and acute stress disorder among college students in China. Applied Psychology: Health and Well-Being 12: 1074-94. [CrossRef]

Yoshizaki, Hugo T. Y., Irineu de Brito Junior, Celso Mitsuo Hino, Larrisa Limongi Aguiar, and Maria Clara Rodrigues Pinheiro. 2020. Relationship between panic buying and per capita income during COVID-19. Sustainability 12: 9968. [CrossRef]

Yuen, Kum Fai, Xueqin Wang, Fei Ma, and Kevin X. Li. 2020. The psychological causes of panic buying following a health crisis. International Journal of Environmental Research and Public Health 17: 3513. [CrossRef] [PubMed]

Zhang, Melvyn, and Helen Elizabeth Smith. 2020. Digital tools to ameliorate psychological symptoms associated with COVID-19: Scoping review. Journal of Medical Internet Research 22: e19706. [CrossRef] [PubMed]

Zhao, Nan, and Guangyu Zhou. 2020. Social media use and mental health during the COVID-19 pandemic: Moderator role of disaster stressor and mediator role of negative affect. Applied Psychology: Health and Well-Being 12: 1019-38. [CrossRef] 